\title{
Décès du professeur Stanislaw E. Nahlik
}

C'est avec une profonde tristesse que le CICR a appris le décès du professeur Stanislaw E. Nahlik, survenu le 5 novembre 1991, à l'âge de 80 ans.

Les membres du Comité international et bon nombre de ses collaborateurs qui l'ont bien connu ressentent vivement la disparition de celui qui fut un grand humaniste de notre temps, consacrant sa vie à la défense et à la promotion du droit.

Né le 8 mai 1911 à Lwów (Pologne), Stanislaw Nahlik fit ses études à l'Université Johann-Casimir de Lwów où il obtint en 1933 le grade de magister juris et de magister en sciences politiques. Entré au service diplomatique de la République de Pologne en 1936, il servira successivement au Consulat général de Pologne à Londres, puis à l'ambassade de Pologne à Berne, de 1939 à 1946.

Après avoir obtenu son doctorat en droit à l'Université Jagellonienne de Cracovie en 1948, Stanislaw Nahlik se consacra essentiellement à l'enseignement supérieur, notamment à Cracovie et à l'Université Copernic de Torún.

De 1962 à 1981, il sera titulaire de la chaire de droit international public à l'Université Jagellonienne de Cracovie et sera nommé professeur emeritus de la même université en 1981.

L'œuvre écrite du professeur Nahlik - quelque 400 ouvrages et articles, dont environ 80 en anglais, français et allemand - offre un éventail impressionnant d'études consacrées aux divers aspects du droit international public; elle lui a conféré une grande notoriété, non seulement en Pologne où ses traités et manuels sur le droit international public, le droit des relations diplomatiques notamment font toujours autorité, mais aussi au-delà des frontières. Ainsi il fut invité à enseigner dans les universités d'une vingtaine de pays et fut nommé docteur honoris causa des Universités de Bordeaux (en 1973) et de Bochum (en 1985).

Membre de plusieurs sociétés de droit européennes, le professeur Nahlik participa à de nombreuses conférences internationales et réunions d'experts, notamment sur la protection des biens culturels dont il s'était fait une spécialité ainsi que sur le droit international 
humanitaire. ${ }^{*}$ Ainsi présida-t-il dès 1975 la Commission II de la Conférence diplomatique sur la réaffirmation et le développement du droit international humanitaire applicable dans les conflits armés (Genève, 1974-1977).

D'une grande finesse d'esprit et d'une exquise courtoisie, il n'avait pas son pareil pour fasciner ses étudiants ou son auditoire par ses connaissances étendues, ses dons pédagogiques, la maîtrise du verbe qu'il savait émailler d'humour. Enfin, l'homme était profondément humain, il sut faire partager son attachement à l'idéal de la CroixRouge en prodiguant durant de nombreuses années ses conseils à la Croix-Rouge polonaise et il contribua activement, en étroite collaboration avec le CICR, à la diffusion du droit international humanitaire en Pologne et sur le plan international.

Le CICR gardera un souvenir ému et reconnaissant de ce grand serviteur de la cause humanitaire.

* Parmi ses cuvres notoires, nous citerons notamment deux cours présentés à l'Académie de droit international de La Haye: «La protection internationale des biens culturels en cas de conflit armé» (RCADI, vol. 120, 1967, pp. 61-136) et "L'extension du statut de combattant à la lumière du Protocole I de Genève de 1977 (RCADI, vol. 164,1979 , pp. 171-249) et «Précis abrégé de droit international humanitaire», in Revue internationale de la Croix-Rouge, $\mathrm{n}^{\circ}$ 748, juillet-août 1984, pp. 195-236. 